\title{
Putting the clock back 30 years: neonatal care since the 1991 NHS reforms
}

\author{
Catherine Pope, David Wild
}

The future of specialist services like neonatal intensive care seems to have been overlooked in the latest round of NHS reforms; yet the changes introduced by the NHS and Community Care Act 1990 may well have important consequences for such services. This paper examines the development of policy for the care of neonates, in particular the establishment of regional neonatal intensive care centres. It is based on informal interviews conducted with clinicians and policy makers concerned about the future of the services they are responsible for. The paper argues that current policy to devolve neonatal intensive care services is in opposition to established clinical opinion, and further, that it may actually contradict some of the stated aims of the white paper.

In line with government thinking in other areas, the NHS white paper, Working for Patients (1989), aimed to decentralise control of health care, and encourage competition. A central tenet of the reforms was the devolution of decision making in the NHS hierarchy - from region to district, and from individual districts to individual units. Whatever the ideological and/or political objections to this new look NHS (and there were many) there were some areas of health care provision where the new ideas could and, if the evidence so far is to be believed, did work. ${ }^{2}$ Out in the districts, providers who knew what they could provide and to whom, in relatively stable areas like elective orthopaedics, found contracting services fairly straightforward. At regional level the focus shifted towards evaluation and auditing services rather than organising and directing them.

According to the white paper, supraregional specialties (such as the national heart and liver transplant programmes) would continue to require centralised funding and coordination, but, it suggested, regional and supradistrict services could be incorporated into the contracting process. The assumption that neonatal intensive care could be coordinated and funded at district level appears flawed for several reasons. The clinical evidence and literature support regional provision of neonatal intensive care. The current pattern of provision is informed by both the clinical evidence and the advice of numerous governmental committees. In addition, as this paper suggests, devolution of neonatal care may compromise patient access to services, limit specialist training, and impede the progress of medical research.

\section{Historical precedents for regional neonatal centres}

Thirty years after Dr Crosse founded the premature baby unit at Sorrento Maternity Hospital in Birmingham the Joint Subcommittee of Standing Medical Advisory Committee and Standing Maternity and Midwifery Advisory Committee (1961) recommended the creation of a comprehensive programme of care for neonates. In the same year the Report of Central Health Services Council argued that special care facilities would reduce neonatal mortality. This was formalised by the Sheldon report, ${ }^{3}$ which advocated a two tier system of provision, with special care baby units in each district for low birthweight babies and those with illnesses unique to the newborn, and neonatal intensive care, providing higher level care at specialist teaching centres. As well as centralising expert care the latter were regarded as a prerequisite for training doctors and nurses in the special care required by the illest neonates. Though initially it was suggested that centralisation might increase the risk of infection (either as a result of deprivation of breast milk or nosocomial factors) or the possibility of over aggressive treatment, these fears proved unfounded. The consensus was that 'within each regional health authority one to three neonatal intensive care units should be established to drain the intensive module of neonatal care. Such units should be sited where the high risk obstetric service exists and where specific expertise in neonatal intensive care exists, preferably in association with an academic department of paediatrics'. 4

Three reports of the Social Services Committee during the 1980 s $(1980,1984,1988)$ recommended the addition of a third tier to neonatal services such that all districts should provide short term care, backed up by subregional facilities at larger maternity units and a regional specialist perinatal centre. While the 1985 Maternity Services Advisory Committee report Maternity Care in Action appeared to endorse the earlier two tier system, the sub- 
sequent Royal College of Physicians report (1988) reiterated clinical support for the three tier system. By the mid to late 1980 s the future of regional neonatal and perinatal centres seemed secure. There was strong research evidence that neonatal intensive care was effective in lowering mortality for low birthweight infants ${ }^{5}$ and it seemed that policy makers and clinical practitioners were in broad agreement about the provision of such care.

Most regions had established or were working towards a three tier system for neonatal care when the NHS and Community Care Act effectively abolished the regional framework for centralised services. Following the act six of the English regional health authorities abandoned regional support for neonatal intensive care, six devolved decision making about neonatal intensive care to districts, one has managed to maintain its regional contract, and one is as yet undecided. In the words of one neonatologist, the reforms were tantamount to 'putting the clock back thirty years. Neonatal intensive care is a highly specialised service and what they are doing, I'd compare it to doing renal dialysis or transplants in a general practice. It can't be done'.

Discussing the current situation with clinicians and policy makers it is apparent that there are at least four areas in which devolution of neonatal services is problematic. First the system of financing, both in terms of setting prices and allocating funds. Second, the coordination, and crucially, monitoring and control of such services. Thirdly the place of clinical research in the new system, and fourthly, related to this the future of specialist training and education in the field of neonatology.

In terms of financing, neonatal intensive care poses some peculiar problems, not least because it is a service which involves two patients - the neonate and the mother (or mother to be) - under two separate but related forms of care (neonatal and obstetric). Conventional patient information systems, now used to calculate and record costs, were not designed to link these two costs - nor do they have any facility for including additional extras such as the added hotel costs of accommodating other relatives, like the baby's father. As a result many providers are forced to operate unrealistic flat rate charges for neonatal intensive care. For those providing care, with one eye on the profit margin, such fixed prices are most favourable with average or shorter than average lengths of stay and, by implication, with the least complicated cases. Yet the primary function of intensive care is to provide for the illest, most premature babies, in need of complex and often lengthy, medical treatment. Such cases are likely to be the most unpredictable in terms of costs.

Problems encountered in setting prices for such services are often eclipsed by difficulties in establishing who should be charged. In one Thames region the district of residence for neonatal admissions differs from the district of referral in over $60 \%$ of cases. Some cases may not even come from the UK: one of the
London neonatal intensive care units successfully cared for quintuplets born to a non-UK resident, who had undergone infertility treatment at a private clinic in London. Nationally the expansion of NHS and private fertility treatment programmes, combined with the demographic rise in multiple births, is likely to increase the pressure on neonatal services.

Neonatal intensive care does not come cheap. It is reliant on costly equipment and highly trained staff and the support of relatively expensive services such as medical physics. A recent appraisal of equipment for neonatal intensive care in Trent $^{6}$ suggested that the financial implications of the shortfall in equipment before the reforms may have been overlooked. The ability of smaller, geographically disparate units to sustain comprehensive facilities and obtain diagnostic and clinical support therefore seems questionable.

A further worry surrounding the reforms is that they may encourage the establishment of small, less well equipped neonatal intensive care units. The new system contains few if any effective constraints or controls over those providing neonatal care, and devolution entails the loss of any central coordination and planning of facilities. Related to this there may be little incentive, or indeed financial backing, for smaller units to undertake research or to publish statistical analyses of outcome and effectiveness. Without the longitudinal research currently undertaken by academic departments linked to regional centres it may prove impossible to identify poor outcomes such as handicap or educational impairment. In addition few units will have the resources or research expertise to develop and evaluate new technology or treatment modes in what is a rapidly changing and developing field of medicine.

If smaller units become the norm and research declines this is likely to affect the quality of training for junior doctors and specialist nurses. Such units may never see or treat the full range of neonatal illnesses, and the opportunity for training staff will be missed.

\section{The reforms and beyond}

Some of the financial and organisational difficulties noted above have already become evident since the reforms. In planning terms there are difficulties for regions who have devolved services, and for those attempting to maintain centralised provision. In north east Thames, which has recently issued guidelines for neonatal services based on designated centres, ${ }^{7}$ regional policy makers are aware that they lack formal sanctions to prevent the growth of units outside this framework. North Western Regional Health Authority, which is hoping to maintain centralised neonatal services with some 25 cots over two sites, has voiced concern that other units may 'opt out' by setting up their own neonatal care services. Staffing is also a problem. Before April 1991 North East Thames had actively attempted to respond to demand for neonatal care by funding extra cots and a new consultant post, yet 
the region as a whole continues to suffer from a shortfall in trained staff. Evidence suggests this is not unique to the Thames area. The staff required if most maternity hospitals were to provide neonatal care is more than double that required to provide the safe cover in a regionally planned service. As one neonatologist pointed out, 'there are not enough trained neonatologists or specialist nurses as it is, if you spread them thinly it just can't work'.

Aside from the obvious financial implications, such staffing patterns are in direct conflict with the aims of Achieving a Balance. ${ }^{8}$ Specialties linked closely to neonatology, such as perinatal pathology, may also lack the necessary specialist staff. Currently there is an acute shortage of trained perinatal pathologists in the NHS and at least two English regions have no perinatal pathologists in post.

The impact of devolution is likely to be a reduction in access to neonatal intensive care; one major neonatal care centre in London continues to turn away $50 \%$ of babies referred. This is despite clinical evidence that 'the lowest feasible neonatal mortality rate in the population, however will not be achieved without ensuring that all infants who need such care receive it." 5

Geographical variation in access, and the quality of neonatal services persists, and is unlikely to be reduced by the 1991 reforms. Patient and physician choice may become even more limited by structural constraints and the uneven distribution of resources resulting from the devolution of services. Some areas may benefit from public and charitable pressure to maintain neonatal intensive care, but this may only provide additional intensive care cots, or fund well known units. The current campaign at St Thomas's Hospital, London for funds for a national neonatal and paediatric centre may be one of the successes - but a comprehensive, equitable neonatal service cannot be sustained in this way. In future, it seems that some components of neonatal care may become a luxury, just as they were 30 years ago.

The authors would like to thank Professor W W Holland and Ms M Morgan for their comments on an earlier draft of this paper. The Information Unit is funded by the Nuffield Provincial Hospitals Trust.

1 Williamson JD. Dealing with extracontractual referrals. BMF 1991;303:499-504.

2 Ghodse B, Rawaf S. Extracontactual referrals in the first three months of NHS reforms. BMF 1991;303:497-9.

3 Sheldon $\mathrm{W}$, chair. Report on public health and medical sub jects. No 127. London: HMSO, 1971. (Sheldon report.)

4 Richards $M$, Roberton N. Admission and discharge policies for special-care units. In: Brimblecome F, Richard $\mathbf{M}$ Roberton N, eds. Separation and special care baby units. London: SIMP/Heinemann, 1978:93.

5 Paneth N, Keily J, Wallenstein S, Marcus M, Pakter J, Susser M. Newborn intensive care and neonatal mortality in low-birthweight infants. $N$ Engl $f$ Med 1987;307: in low- 55 .

6 Fenton AC, Field DJ. Shortfall of equipment for neonatal intensive care and the introduction of budget holding intensive care and the introducto

7 North East Thames Regional Health Authority. Regional guidelines for service contracts: neonatal care services. London: Service Development Directorate, NETRHA

$8 \mathrm{UK}$ Health Departments, the Joint Consultants Committee, and the Chairmen of the Regional Health Authorities. Hospital medical staffing: achieving a balance. London: DHSS, 1986 